\title{
Intersectional Dialogue - A Cosmopolitical Dialogue of Ethics
}

\author{
Rebecca Adami
}

Stockholm University

\begin{abstract}
The article is based on a critical cosmopolitan outlook on dialogue as not aimed at reaching consensus, but rather keeping dialogue of difference open, with the ability to reach common understanding of human rights on conflicting grounds. Intersectional dialogue is used as a concept that opens up possibilities to study, in a pragmatic sense, the 'cosmopolitan space' in which different axes of power met in the historical drafting of human rights. By enacting analysis of United Nations (UN) documents from 1948 on the process of drafting the Universal Declaration on Human Rights (UDHR) the conceptualization of intersectional dialogue is put to work. The utopian foundation for deliberative democracy as dialogue in the absence of power and interest does not acknowledge the power bound context in which the human rights were negotiated; where conflicting and sometimes agonistic narratives on the ideological foundation of human rights were debated on an international arena in 1946-48.
\end{abstract}

\section{Introduction}

There are some main challenges faced in a plural world, of conflict and intersection of power, which are not dealt with properly in a traditional view of dialogue as reaching consensus on rational arguments. Inter-cultural dialogue has been one response to cross-cultural conflicts although the paper argues that it can be limiting to discuss culture in a static notion, disregarding the intersection of power and social categories people are moving between in interaction with others (Adami \& Schumann forthcoming). Instead, the paper introduces a new methodological concept, useful for analyzing dialogue in diverse cosmopolitan spaces, which will be elaborated further on in the paper. This cosmopolitan vision and the elusive goal of democratic place-making can be framed in the language of thick and thin as used by Michael Walzer (1994) where ethics and morals are thought of in one’s local context (thick with cultural values that form social boundaries for inclusion) and in more cosmopolitan contexts where the moral considerations reach beyond our close relations and social ties (where thin is associated with universalism, of including everyone on the basis that what grants entry is based on a rather thin set of common values or ideas). The question of power 
and its relation with space is fundamental in considering and recognizing spaces where ethics and rights are negotiated.

Intersectional dialogue acknowledges that people in different power positions intersect in changing relational contexts. Intersectional dialogue hence refers to the way in which power intersects when individuals position themselves in dialogue by drawing on different cultural narratives (Adami 2012). The importance of keeping dialogue open is reached in this sense by putting conflict and agonism at the heart of political dialogue. The paper builds this conception of intersectional dialogue on three main aspects that a traditional view of dialogue fails to acknowledge, namely: 1) how power and interest intersect to frame what is said and by whom 2) how agreement can be agreeing to disagree, keeping conflict at the center of dialogue (Mouffe, 2005; Todd, 2010) and 3) how competing 'truth claims’ can reach universal common ground if dissent about interpretation is respected (White, n.d.).

\section{Dialogue as an Ethical Challenge for Cosmopolitanism - Facing Pluralism}

In a more socially interconnected world characterized by war, conflict and inequality we encounter challenges in safeguarding cosmopolitan ethics such as human rights and at the same time taking into account pluralism and cultural diversity. Human rights as a common ethics based on a shared humanity has been problematized as overshadowing difference in human encounters. Keeping an openness towards otherness while granting human dignity beyond cultural boarders is an ethical challenge regarding human rights. We can see tendencies of a cosmopolitan turn, from a cosmopolitanism focusing on sameness as drawn by Martha Nussbaum (Nussbaum, 1998), to a more pluralism-oriented cosmopolitanism, as drawn by Sharon Todd (Todd, 2010). The critical-ethical dimension of cosmopolitanism has been raised in this cosmopolitan turn by urging an awareness of the plurality of voices on different interpretations on rights and duties, generally marginalized under hegemonic power structures in human rights discourses. The notion of a presumed dichotomy of universal notions of human rights and contextually rooted cultural, ideological and religious values (Mutua, 2002) seems to question the very notion of universally claimed human rights. Lynn Hunt (2007, p. 36) asks how the invention of universal human rights in the eighteenth century could become thinkable when several categories of persons - women, the poor, Blacks were considered subservient and unequal? 
When doing analysis on historical declarations like the Universal Declaration of Human Rights, it is important not to regard the text as being without authors. Many scholars (Hunt, 2007; Mutua, 2002) have assumed that the declaration was the result of the work of a few western delegates to the UN, who dominated the thinking and wording of human rights as based in western humanism and natural law. Scholars such as Michael Ignatieff (Ignatieff \& Gutmann, 2003) and Makau Mutua (Mutua, 2002) have argued that human rights are a western project, in need of contestation and re-articulation from other cultural perspectives. This is the dominant view of the creation of human rights in the UDHR, which has overshadowed other voices in international relations on delineations and different cultural and ideological foundations for universal human rights.

The ways in which to read and analyze political and international policy texts on human rights are vast, however a traditional approach to policy 'as based upon idealist assumptions about the nature of language itself which take it to be a transparent vehicle for the transmission of information, thoughts and values' (Codd, 1988, p. 235) has been criticized by John A Codd (1988), who argues for policy analysis to examine the effects the text has on readers and to 'expose the ideological processes which lie behind the production of the text' (Codd, 1988, p. 235). The readers of the Universal Declaration of Human Rights interpret the text into their own context and the UDHR has been translated into more than 370 different languages, which makes it among the most translated documents in the world. Codd (1988) argues that these kind of texts "contain divergent meanings, contradictions and structured omissions” (Codd, 1988, p. 235) so that it has different meaning for different readers. In order to analyze the ideological processes that lie behind the production of the UDHR, I have developed the analytical concept of "intersectional dialogue" to capture how power struggles frame dialogues and hence influences the leaving out of references to particular values in the text, making agreements to disagree possible. Codd names this critical analysis a form of “textual deconstruction” (Codd, 1988, p. 235).

A significant number of scholars have acknowledged the lack of effective intersectional methodologies in policy analysis (Hancock, 2007; Nash, 2008; Phoenix \& Pattynama, 2006). Efforts to move beyond one-dimensional policy analysis are met with challenges in applying an intersectional approach since there is a lack of clearly defined intersectional methodology. Various tools to operationalize intersectionality have been developed (Crenshaw, 2006; Parken, 2010; Symington, 2004). These methods aim at illuminating how social categories of 
difference intersect in constantly changing ways in order to expose undemocratic dialogues (Hankivsky et al., 2010). Nira Yulu-Davis (Yuval-Davis, 2006), Myra Ferree (Ferree, 2009) and Birte Siim (Siim, 2011) have all argued for the need to enact analysis of intersectionality on regional and international levels.

The UDHR may seem to be rooted in western thinking, but reading the policy document only reveals the resulting text, not the process towards it. I argue, following Codd's critique, that it is important to take into account who wrote the text and in what historical context, in order to make the declaration more transparent for its readers. Such a reading may question the dominant narrative on human rights as western, and additionally re-vitalize the importance of research into different ideologies and faiths that ground human rights in other, non-western, philosophies. Hunt argues that the invention of human rights was made possible due to western philosophy, hence she traces the discourse on human rights to a Eurocentric doctrine, neglecting the actual people who participated in drafting the UDHR, coming from all corners of the world. I argue that in order to understand the impact of the UDHR internationally and its potential for social and political re-imagination in diverse contexts, the process leading up to the first international document of human rights needs to be further researched by studying the vast historical material from the UN Archives and the UN Dag Hammarskjöld Library.

To see human rights as a western universalism seems to be underpinned by a notion of dialogue as reaching consensus on common philosophical and ideological ground that underscore the argument that the actual working process when human rights were drafted in 1948 was a process characterized by domination of western thoughts. The primary sources from 1946-48 reveal quite the opposite.

\section{Towards a Cosmopolitical Notion of Dialogue}

This historical process of creating the UDHR, when seen as a process of efforts for dialogue on an international arena, has been interpreted, I argue, through a dominant Habermasian view of dialogue as in absence of power relations, where so called "less-rational” arguments had minor influence on the creation of the text, a text hence built on consensus about the philosophical and ideological foundation of human rights. The view of deliberative dialogue, characterized by thoughts on rationality and consensus, has been developed by Jürgen Habermas (1984) and later Sheyla Benhabib (Benhabib, 2006). The aim of reaching consensus in dialogue can, according to Habermas, be reached based on an ideal 
communication, where reason and argument leads the rational being to the best decisions. Habermas does mention symmetry between the participants and sets up criteria for the ideal communication situation, but he does not in his earlier work elaborate on the causes or consequences of social inequality or oppression, hence the theoretical point lacks a perspective of power analysis. How can dialogue be understood in a pluralistic world, with conflicting worldviews and diverse morals of agonistic value systems and cultural morals?

Mikael Carleheden (Carleheden, Lidskog, \& Roman, 2007) criticizes the theory of Habermas (1984) for not acknowledging power positions, and argues that it neither considers social inequality nor cultural pluralism. Studying international policy work and international efforts for dialogue surrounding the creation of declaration, conventions and other proclamations, the policy texts in themselves may not reveal the tensions and conflicts over meaning and words, that preceded their drafting. Neglecting these power debates and negotiations risks losing the dimension of ambivalence and the openness in policy texts on human rights for different and opposing interpretations and readings. Hence, some of the political imaginary of human rights may be lost in universal declarations like the UDHR through de-contextualized and de-historicized readings of the text.

Benhabib (2002, 2006) proposes ‘translation’ between particular and universal notions of human rights in order to enhance local and cultural claims in relation to universal aspirations on rights. Such international efforts to create regional and international arenas for discussing human rights practices risk de-legitimizing the role of conflict in democratic practices, I argue, if the 'local' and 'particular' is exclusively linked to non-western claims, whereas the 'universal' is conflated with western notions of human rights, as based on a certain kind of individualism and liberalism.

Chantal Mouffe (2005) has stressed the importance of keeping conflict at the center of such dialogue, in order to accept that hegemonic power structures are at work in any dialogue. Mouffe (2005) aims her critique, not at the concept of human rights, but at the institutions that are supposed to uphold the notion of human rights, and she suggests that conflict over interpretation regarding human rights is what keeps dialogue open for different and agonistic opinions. She presents a pluralistic democratic alternative by introducing the concept of 'conflict consensus' arguing for the need of collisions between different political positions and critiques a traditional view of dialogue, for not taking into account conflict and dissent 
about interpretations, since the aim of consensus and harmony actually put at risk political solutions to questions of cross-cultural conflict (Todd, 2010, p. 105).

Crucial in this argumentation towards a more conflict-oriented analysis of dialogue that acknowledges how power intersects in human relations, is a problematization of the conflation of universalism with western notions of human rights and local interpretation with non-western cultures, since without this problematization any effort to truly contextualize international documents may reify hegemonic notions of the concept of 'human rights'. Paternalistic notions of universality generally accompany a traditional view of dialogue as leaning towards universalism where the rational is equalized with dominant narratives of 'truth claims'. As Todd notes, 'both within certain strands of cosmopolitanism itself and within democratic theory broadly speaking, there exists a deep suspicion of such universal aspirations' (2010, p. 216). Todd not only takes into account difference and pluralism in discussing human rights but equally faces conflict in dialogue which she says non-critical cosmopolitanism fails to acknowledge. This notion of agonistic cosmopolitics is what the paper leans towards in re-thinking dialogue through an intersectional approach.

\section{An Ethical Dimension of Dialogue}

In order to take into account not only what was spoken but also the actual concrete beings who participated in the debates, the paper draws on Michael Bakhtin's notion of an aestethic approach to dialogue (Bakhtin 2004). To be aesthetic in a Bakhtinian sense is to contribute value to another by seeing the dialogue from without and trying to see what can be seen by another. In other words to give legitimacy to one's opponent by seeing what makes sense from the other position, even though the opponent's position might seem remote to oneself. 'An aesthetic approach creates room for the individual, as a unique personality, to remain unfinalized, incomplete and with a capacity to change and contribute in dialogue throughout the life span, ${ }^{1}$. Hence an ethical challenge with dialogue and any analysis of dialogue is to leave room in the analysis for people's uniqueness, influenced and changed throughout individual lifespans rather than analyzing meaning limiting people within cultural or social categories. It is upon this notion of people's uniqueness that a narrative approach to intersectionality is valuable, in order to understand how individuals position themselves in dialogue by orienting

\footnotetext{
${ }^{1}$ E. J. White, 'Bakhtinian Dialogism: A Philosophical and Methodological Route to Dialogue and Difference? EJ White Victoria University of Wellington, New Zealand PO Box 17-310’ (n.d.), accessed January 29, 2013.
} 
themselves in relation to their experience of interactions, practices and cultural narratives embedded in their life stories. However, without acknowledging how power and oppression can silence individuals in dialogue, the critical notion of intersectionality loses its potential of exposing hegemony. Intersectional dialogue enhances the notion that people position themselves differently depending on context and intersection of power due to that positioning where cultural narratives play the role of relating meaning to known value systems (Adami 2012). Dissent about interpretation of ‘universal human rights' is acknowledged when analyzing dialogue as intersectional.

Post structural, post colonial and feminist perspectives have represented alternative, counter narratives of particularism to this dominant narrative of universality. In the notion of intersectional dialogue developed in the paper, it is held that people draw on particular or cultural narratives when positioning themselves in relation to dominant narrative of universality.

\section{Exposing Power in Undemocratic Dialogues}

Looking at the primary sources from the UN and the UNESCO archives and building on earlier research on the drafting of the UDHR (eg Morsink, 1999; Lauren, 2011, Glendon, 2001, Adami, 2012), a different picture than a consensus oriented process emerges, which cannot be captured adequately in its complexity by a model of dialogue in the absence of power and conflict. Rather, the drafting process of the UDHR in 1948 was a power struggle after the Second World War between East and West (of different values and political ideologies), between North and South (of colonialism and national independence), and between an inclusive or exclusive understanding of equality and humanity ( as referring to only men or to women and men). During the drafting of the UDHR in 1946-48, representatives from different continents, countries, religions, political systems and traditions met on a diplomatic arena, forced into dialogue and compromise for the universality of the human rights they wanted to defend in contrast to the atrocities of the World War Two. In order to expose this process in the reading of the UDHR, there is a need for a new way to theorize the social and political conflicts that occurred in the aftermaths of the World War Two. It is against this background of power relations between individuals and groups in this historical and specific context, I argue, that the development of an intersectional alternative to intercultural dialogue is needed. Intersectionality as used in the paper should be understood as not only regarding intersections of power in discourse but also taking into account the actual 
individuals giving voice to the spoken. This notion of intersectionality as the positions that individuals take in different arenas will be elaborated further on. Intersectional dialogue reframes the conflict between particular and universal in international policy development on human rights through its emphasis on relationality that makes every contextual and historical encounter unique in how power intersects in dialogue.

By introducing the analytical concept of intersectional dialogue the paper takes into account the notion of conflict and tensions faced in aspirations for cosmopolitan dialogue on universal ethics and values, such as human rights. Secondly, by referring to the working process of drafting the UDHR in 1948 as a cosmopolitan space (cf. Schumann \& Adami forthcoming) the paper leans towards what has been referred to as critical cosmopolitanism, a critique against cosmopolitanism as a universalism in the sense of polite tolerance. Space is used to illustrate how people from different cultural backgrounds met in a certain time and place with a common task to negotiate on cosmopolitan ethics in a declarative sense. Critical cosmopolitanism takes conflict and imperfection of human beings into discussions on coexistence and on the common claim for universal human rights. The dichotomy which has not yet been reconciled theoretically between universal values and particular cultural values is met pragmatically in the paper by exploring their relation in a specific historical and relational context, in 1948 (Adami, 2012).

\section{Background to the Drafting of the Universal Declaration on Human Rights}

The tensions in the world were strong after the Second World War. The UN Commission which had been appointed for the task of drafting an international bill of rights faced great challenges in cooperating since the conflicts between the Soviet Union and the USA were fought as an ideological battle between communism and liberalism, and the de-colonization and increase of independent states led to an increase of member states in the UN and in the light of political claims for equal rights of women. Delegates representing post colonial countries met in discussions with their colonial rulers, delegates from what would become the power struggle between the East and West block in the Cold War after the Second World War met from opposite sides of economic ideologies and Islamic nations met with former Christian crusaders. In other words, the historical context for the drafting process challenged power positions, creating a possible conflict zone with domination of some over others (Adami 2012). Still, the de-stabilization of international relations through the World War 
Two and the shared condemnation of the defeated Nazi Regime, created a window of opportunity for the delegates who were assembled from different parts of the world to create and vote through a universal declaration on rights and duties of people. In such times of social change, intersection of conflict and cohesion were at work. When studying the international policy process of drafting the UDHR in 1948 that included people from different cultures and ideological background, divisions that were transformed into dialogue, recognition and inclusion can be analyzed.

At the first session of the Drafting Committee, the UK delegate reminded his colleagues 'of the historical situation in which the Committee met. It was one, he said, where Germany and other enemy countries during the war had completely ignored what mankind had regarded as fundamental human rights and freedoms. The Committee met as a first step toward providing the maximum possible safeguard against that sort of thing in the future. ${ }^{2}$ In this historical context, there was a collective aim of the delegates, limiting a static dominance of some over others and enhancing a kind of dialogue where the power positions were under constant change and negotiation. It took three weeks for the 58 delegates from different parts of the world to first negotiate and discuss and later pass two articles in the Declaration. After a whole month the delegates had passed only three out of thirty articles. The delegates met over hundred times, which gives an idea of how tense the power relations were within the UN Commission and how much time it took for all delegates to debate different aspects of human rights.

The "fathers" of the UDHR have been referred to as René Cassin (Lauren, 2011) and John Humphrey (Morsink, 1999) although it is questionable if this can be taken for granted, since their initial drafts that emphasized the rights of Man were reworked in more than seven versions of the UDHR. The UDHR was written at a time when colonial empires started to break up. It could be presumed by this that the colonial powers dominated the discussions when in fact two of the most influential drafters, the delegation from Lebanon and from the Philippines, were from countries gaining their independence in 1946, the year the UN Commission was established. Syria also joined that year. In 1947 India, Burma, Pakistan gained their independence; both India and Pakistan played an active role in the drafting process. In 1948, 56 member states to the UN voted for the Universal Declaration on Human

\footnotetext{
${ }^{2}$ UN Archives, E/CN.4/AC.1/SR.7, p.5.
} 
Rights. There was an underrepresentation of African countries in 1948, a fact that would be heavily criticized over the following years, until the World Conference on Human Rights in Vienna 1993, were 177 member states were represented.

The drafting process is too complex and the historical material too rich to be captured in this paper, however, I draw on three characteristic aspects of the drafting process that points back to the conceptual framework of "intersectional dialogue" to illustrate some examples on how different intersections of power framed the dialogue. I focus particularly on the impact of colonial power structures and how these positions between newly independent state delegates and delegates from colonial powers, such as England and France, were re-negotiated during the drafting process, especially in the question of rights for people under colonial rule. Secondly, I expose how disagreements were a basis for agreement, and how this acknowledgement of keeping conflict at the center of dialogue is crucial in intersectional analysis of dialogue. Thirdly, I highlight the influence of the women delegates to the UN (who, although in great minority, held power positions related to other positions than gender) and how the East-West power relation impacted on the enforcement of gender-neutral language in the final UDHR text. Using the conceptual framework of "intersectional dialogue” when analyzing the primary UN sources from 1946-48 raises questions that focus on: Who participated? What axes of power were operating in the discourse? How did the delegates position themselves in relation to each other, in terms of influence over the discussions and voting, during the debates? Whose voice was heard and to what extent? From these questions evolves a different picture than a consensus oriented drafting process, portraying the endless negotiations and changes in power positions during the creation of the UDHR.

\section{Power Bound Dialogue Within the UN Commission on Human Rights}

In June 1946 the UN Commission on Human Rights was established. During the two years it took to draft the UDHR, the member states of the UN had increased due to the number of newly independent states that before the Second World War had been under colonial rule (like India and Pakistan). The colonial powers, joined by nations form Latin America, did not support the inclusion of human rights in territories under colonial rule. Still, voices were raised from a number of states for the rights of people living under colonial rule. Even though the delegate from the Philippines, Romulo, was representing a former colony in relation to England's delegate, Noel Baker, who represented a colonial power, Romulo had a strong 
rhetoric in human rights as a journalist who had won the Pulitzer Prize for articles predicting the end of colonialism. With the pressure from human rights activists and media covering the work in the UN Commission, it was hard for the colonial powers to neglect the arguments for human rights for 'dependent people', as people living under colonial rule were called. Hence, in the UDHR, there was no mention of "rights of citizen's" but "everyone, regardless of nationality or place of residence" were entitled to all the rights set forth in the declaration.

There were a few women in the UN Commission, Eleonor Roosevelt, delegate from USA and Hansa Metha, delegate from India. As the only female delegates to the UN Commission, their voices risked being marginalized, but looking from an intersectional approach, we see that other power positions were at work than the gender based. Eleonor Roosevelt was delegate from one of the great powers, and widow to the American president Franklin Roosevelt. She was in a power position both regarding class, race, nationality and political influence in relation to many male delegates in the UN Commission. She also acted as chair in the UN Commission. Hansa Metha, the Indian delegate was a legislator, an activist in the movement that led to India's independence in 1947 and had been a sharp, outspoken critic of Britain's colonial policies (Glendon, 2001).

The delegate from India, Metha, said 'she did not like the wording of 'all men' or 'should act ...like brothers'. Such phrases, she said 'might be interpreted to exclude women, and were out of date. ${ }^{3}$

The rhetoric used by the delegates who were in a power position of not being affected by gender-based discrimination was focused on a language, which to them seemed neutral and inclusive. The term 'all men', which was used in the first drafts of the declaration, was according to many delegates gender neutral, based on the argument that women were included in the term 'men'. One could assume that Eleonor Roosevelt, as a woman and from a liberal USA would have fought for inclusion of women's rights in the debates, but she often took a gender-blind position and did hence not understand why 'all men' would not include all women too. In the UN Commission, though, there were women like Hansa Metha, who had fought for the equal rights of women in India and she argued for changing the wording of 'all men' to 'everyone' ${ }^{4}$. Gender is one of many parameters influencing claims of rights, and

\footnotetext{
${ }^{3}$ UN Archives, E/CN.4/SR.34, p.4

${ }^{4}$ ibid.
} 
it is interesting to note that the male delegates of the UN Commission from the Communist countries fought for the inclusion of a gender-neutral language, based rather on their ideological conviction. The wording 'all human beings’ was approved, which frees Article 1 of sexist implications.

When the article on right to work and equal pay was voted on, neither Eleonor Roosevelt nor Hana Metha voted for the adoption of specific mention of non-discrimination of women in such an article.

The BSSR delegate expressed his astonishment that the representative of India, herself a woman, was opposed to paragraph 4 (mentioning nondiscrimination against women regarding pay). The importance of such a provision was great, in view of the fact that women had been discriminated against in the matter of pay almost more than in any other aspects. Moreover, the Commission on the Status of Women had adopted a resolution, requesting that the Declaration should contain a provision with regard to equal pay for equal work. ${ }^{5}$

That Hansa Metha and Eleonor Roosevelt were against specifying nondiscrimination of women was not because they objected to equal rights to equal pay, but because they felt that any specific mention of women in the article would have rendered weaker the sense of inclusion of women in the term "everyone" in other articles of the declaration. The representative of UK declared that, 'in spite of the arguments of the USSR representative, he would be guided by the views of the two female members of the UN Commission ${ }^{6}$. Does this illustrate that women have greater influence in debates on human rights of women than men? I argue that an intersectional dialogue contains complex power relations that are under constant negotiations, which means that when people meet in cosmopolitan spaces, their belonging and rational for argumentations cannot be limited to analysis that focuses only on gender, culture, ethnicity or faith, but depend on how they want to position themselves in relation to a multitude of social belongings, connected to diverse cultural narratives.

\footnotetext{
${ }^{5}$ UN Archives, E/CN.4/SR.66, p.6

${ }^{6}$ UN Archves, E/CN.4/SR.66, p.6
} 


\section{Giving Legitimacy to Ones Opponents - or Agreeing to Disagree}

The UN Commission held over hundred sessions between 1946 and 1948 and governments appointed individuals with the capacity for rhetoric and intellectual debates; there were professors, authors, diplomats and human rights activists, who could discuss human rights through different perspectives.

China named Dr. Peng-chun Chang, a former professor, 'highly knowledgeable about the West, Islam and Arabic culture, yet deeply committed to Confucianism and the values inherent in Asian culture and philosophy'. Lebanon appointed Dr. Charles Habib Malik, a former professor of philosophy, personally and professionally shaped by both Christianity and Islam. The Philippines selected Carlos Romulo, public official and devoted Catholic, who won the Pulitzer Prize for journalism' (Lauren, 2011, p. 207).

Any common ground that could lead to satisfying answers as to what was meant with concepts such as ‘by nature', 'inalienable', inherent', 'reason', ‘conscience' or 'morality’ was hard to find, viewed through various philosophical, religious (and nonreligious), and ideological perspectives. The delegates in the UN Commission sought to discover universal principles by creating a discourse 'wherein no regional philosophy or single way of life was permitted to prevail’ (Lauren, 2011, p. 209).

The UN Commission asked UNESCO if they could initiate an inquiry on the philosophical foundation for universal human rights. UNESCO appointed a Committee of philosophers who consulted great thinkers from all over the world, and assembled their written replies. The UNESCO Committee conducted parallel work to the UN Commission, which resulted in a \ list of universal human rights principles similar to the UDHR. This fact has not received much attention in earlier research (Adami, 2012). The workings of the UN Commission and the UNESCO Committee were different, the UN Commission being a political arena for individual delegates giving lengthy speeches in order to influence each other's opinions, whereas the UNESCO Committee handled their work through written reports from various parts of the world. UNESCO's part was to consult philosophers and assemble their replies. 'They thus invited one hundred and fifty very different leading intellectuals to send their thoughts on the specific philosophical questions raised by international human rights' (Lauren, 2011, p. 210). The report of the UNESCO Committee's work, 'Human Rights Comments and Interpretations', consists of fundamentally different conceptions of human 
rights, ranging from Islam to Communism and Hinduism and of competing interpretations on the philosophical foundation of universal human rights. Human rights were referred to as 'practical principles' in the UNESCO Committee, since these intellectuals agreed that there could not be an agreement on philosophical principles, but rather practical principles that could be understood through competing moral systems.

Even though the philosophers could not find agreement on a philosophical foundation for universal human rights, they found legitimacy in each and every ideology, philosophy and religion that was represented in their philosophical inquiry, for universal human rights as practical principles for action. Mahatma Ghandi contributed with a text discussing the importance of duty towards one another. The question of duties was incorporated in the final draft of the UDHR in article twenty-nine, 'Everyone has duties to the community in which alone the free and full development of his personality is possible' (UDHR, article 29). The Chinese representative discussed how human rights could be traced in Asian history and be understood in relation to Confucius and humaneness as an ethical stance in social relations. The Islamic representative explored how human rights needed to be secured within a society, where security was fundamental for human beings in relation to food and clothing, housing, education and health. Jacques Maritain, who was the chair of the UNESCO Committee, wrote in the foreword to the report,

\footnotetext{
How, I asked, can we imagine an agreement of minds between men who are gathered together precisely in order to accomplish a common intellectual task, men who come from the four corners of the globe and who not only belong to different cultures and civilizations, but are of antagonistic spiritual associations and schools of thought? Because, as I said at the beginning of my speech, the goal of UNESCO is a practical goal, agreement between minds can be reached spontaneously, not on the basis of common speculative ideas, but on common practical ideas, not on the affirmation of one and the same conception of the world, of man and of knowledge, but upon the affirmation of a single body of beliefs for guidance in action. (UNESCO, 1948)
}

\section{Confronting Conflicting 'Truth Claims' - Dissent about Interpretation}

There were different interpretations on the Islamic faith within the UN Commission. When it came to freedom of religion in the Declaration, conflicts arose between different Moslem delegates. In countries where religion and politics were separated, the freedom of religion 
was viewed as an individual choice; the Lebanese delegate pointed out that freedom of religion also meant the protection of the inner being of each individual ${ }^{7}$.

Article 18 on freedom of religion had not prevented other Muslim countries, like Syria, Iran, Turkey and Pakistan from voting for the Declaration, though the Saudi Arabia delegation abstained from voting on the article on freedom of religion. The Danish delegate supported this perception of the Muslim faith, saying that: 'the adoption would mean that the representatives of 300 million Mohammedans would be unable to support the draft declaration' ${ }^{8}$. The Indian delegate replied that the Indian constitution included 'the right to convert or be converted; that applied to the 40 million Moslems of India as well as to all others' ${ }^{9}$. There was another conflict about religious faith in the UN Commission regarding article one in the Declaration. The debate concerned inclusion or exclusion of reference to God or Allah in the first article of the UDHR, which today reads:

All human beings are born free and equal in dignity and rights. They are endowed with reason and conscience and should act towards one another in a spirit of brotherhood. (UDHR, article 1).

The South American delegations argued that faith was uniting people from all over the world and created understanding between people. There was a majority of religious states in the UN Commission, but a majority did not mean domination and the dissent of interpretation was acknowledged, by leaving out reference to God in the final text. We can today find in the first article in the UDHR that reference to 'God', 'Allah' and 'by nature' was excluded from the text, asserting freedom and dignity of everyone without reference to any particular ideology, philosophy or faith. The dissent on why human beings should be seen as born free and equal in dignity and rights was respected, leaving the current text open for interpretation on the philosophical, ideological and religious foundation on universal human rights.

\section{Conclusion}

In 1948, people from all over the world met during intense discussions in over hundred sessions to claim universal human rights. Exploring the drafting of the UDHR as an

\footnotetext{
${ }^{7}$ UN Archives, A/C.3/SR.128, p. 405

${ }^{8}$ UN Archives, A/C.3/SR.128, p. 407

${ }^{9}$ UN Archives, A/C.3/SR.128, p.407
} 
intersectional dialogue, the importance of taking pluralism into account became evident. Universal human rights needed to make sense in a plural world. According to Todd, agonism and conflict keep dialogue open when put at the center of discussions, rather than being silenced by domination and forced consensus. The UDHR was reached on conflicting grounds with dialogue between people of different faith, sex, culture, political conviction, class-generated conflicts, based on different morals and beliefs. Examples of opposing world views in the UN Commission, that was set up to draft the declaration, was between the Soviet Communist regime and South American Catholic countries and between the apartheid system in South Africa and all other countries represented in the UN Commission. Human rights were hence interpreted differently by the delegates of the UN Commission, by the Saudi Arabia in contrast to India on the Islamic faith regarding freedom of religion and the right to convert to another religion. Discussions on the origin of human rights illuminated the contradiction between natural law and divine origin of human beings, though these opposing perspectives were coincided by excluding reference to particular values in the declaration (Adami, 2012). All these different views and perspectives collided when delegations from opposing ideological contexts met in what has been referred to in this paper as 'intersectional dialogue'. Without neglecting the participation of western delegates to the UN Commission on Human Rights, one finds counter narratives in the primary sources from the UN archives, contrasting the western-oriented notions that have been re-enforced in contemporary interpretations of the UDHR.

The concept of intersectional dialogue illustrates that people have a multitude of belongings; one person can hold different identities and represent different belongings depending on the social context, hence intersectional dialogue exposes hegemony and multiple oppression. A person's experience does not have to coincide with how others categorize the person, but rather has relational, contextual and situational dimensions. Using this analytical concept of intersectional dialogue when studying primary sources of UN documents from 1948 envisages how power structures intersected when people from all over the world met in dialogue over universal human rights. Intersectional dialogue as an analytical concept can be used in future research on policy and dialogue - enabling discussions on ethical challenges of power and pluralism.

By enacting analysis of the drafting process of the UDHR, I emphasised in the paper how conflict was kept at the center of the dialogue, in that the delegates gave legitimacy to their 
opponents in debates, hence did not force an unjust consensus for the approval of the UDHR, but rather let the incompatible and antagonist cultural, religious and political values held by the delegates serve as the ground for a universal acceptance of human rights.

\section{References}

Adami, R. \& Schumann, C. forthcoming, 'Towards a Critical Cosmopolitanism in Human Rights Learning: The Vienna Conference in 1993’, in Papastephanou, M., Strand, T. \& Pirrie, A. (eds.), Philosophy as a Lived Experience: Navigating through dichotomies of thought and action, VDM Verlag, Berlin.

Adami, R. 2012, 'Reconciling universality and particularity through a cosmopolitan outlook on human rights', Cosmopolitan Civil Societies: An Interdisciplinary Journal, vol. 4, no.2, pp. 22-37.

Bakhtin, M. M. 2004, 'Dialogic origin and dialogic pedagogy of grammar: Stylistics in teaching Russian language in secondary school', Journal of Russian and East European Psychology, vol. 42, no. 6, pp. 12-49.

Benhabib, S. 2002, The Claims of Culture: Equality and Diversity in the Global Era, Princeton University Press, Princeton N.J.

Benhabib, S. 2006, Another Cosmopolitanism, Oxford University Press, Oxford.

Carleheden, M., Lidskog, R., \& Roman, C. 2007, Social interaktion : förutsättningar och former, Liber, Malmö.

Codd, J. A. 1988, 'The construction and deconstruction of educational policy documents', Journal of Education Policy, vol. 3, no.3, pp. 235-247.

Crenshaw, K. W. 2006 'Mapping the margins : intersectionality, identity politics and violence against women of color', Kvinder, køn og forskning vol. 15, no.2/3, pp. 3-20.

Ferree, M. M. 2009, 'Inequality, intersectionality and the politics of discourse', Framing feminist alliances, Lombardo, E., Meier, P. and Verloo, M. (eds.) The Discursive Politics of Gender Equality: Stretching, Bending and Policy-Making, Routledge.

Glendon, M. A. 2001, A world made new : Eleanor Roosevelt and the Universal Declaration of Human Rights, Random House, New York.

Habermas, J. 1984, The Theory of Communicative Action, Volume I, Beacon Press, Boston.

Hancock, A. M. 2007, 'When multiplication doesn’t equal quick addition: Examining intersectionality as a research paradigm', Perspectives on Politics, vol. 5, no. 1, pp. 6379.

Hankivsky, O., Reid, C., Cormier, R., Varcoe, C., Clark, N., Benoit, C., \& Brotman, S. 2010, 'Exploring the promises of intersectionality for advancing women's health research', International Journal for Equity in Health, vol. 9, no. 5, no. 1-15.

Hunt, L. A. 2007, Inventing Human Rights : a History, W.W. Norton \& Co, New York. Ignatieff, M., \& Gutmann, A. 2003, Human rights as Politics and Idolatry. Princeton University Press, Princeton N.J.

Lauren, P. G. 2011, The evolution of International Human Rights : Visions Seen, University of Pennsylvania Press, Philadelphia, Pa. 
Morsink, J. 1999, The Universal Declaration of Human Rights : origins, drafting, and intent, University of Pennsylvania Press, Philadelphia, Pa.

Mouffe, C. 2005, On the political, Routledge, London.

Mutua, M. 2002, Human Rights: A Political and Cultural Critique, University of Pennsylvania Press, Philadelphia, Pa..

Nash, J. C. 2008, 'Re-thinking intersectionality', Feminist Review, vol. 89, no.1, pp.1-15.

Nussbaum, M. C. 1998, Cultivating humanity : a classical defense of reform in liberal education, Harvard University Press, Cambridge, Mass.

Parken, A. 2010 'A multi-strand approach to promoting equalities and human rights in policy making', Policy \& Politics, vol. 38, no. 1, pp. 79-99.

Phoenix, A., \& Pattynama, P. 2006, 'Intersectionality', European Journal of Women's Studies, vol. 13, no. 3, pp. 187-192.

Sack, R. D. 1997, Homo Geographicus : A Framework for Action, Awareness, and Moral Concern, Johns Hopkins University Press, Baltimore.

Siim, B. 2011, 'Democratic Theory and the Practice of Intersectionality: Gender and Diversity in the European Public Sphere', APSA 2011 Annual Meeting Paper, Available at SSRN: http://ssrn.com/abstract $=1902792$

Somers, M. \& Gibson, G. 1993 'Reclaiming the epistemological "other": narrative and the social constitution of identity' CSST Working Paper 94, University of Michigan, http://deepblue.lib.umich.edu/bitstream/handle/2027.42/51265/499.pdf?sequence=1 Retrieved February 5, 2013.

Symington, A. 2004, 'Intersectionality: A tool for gender and economic justice', Women's Rights and Economic Change, vol. 9, pp. 1-8.

Todd, S. 2010, Toward an Imperfect Education: Facing Humanity, Rethinking Cosmopolitanism, Paradigm Publishers.

Walzer, M. 1994, Thick and Thin : Moral Argument at Home and Abroad, Univ. of Notre Dame Press, Notre Dame, Ind.

White, E.J. 2009, 'Bakhtinian dialogism: A philosophical and methodological route to dialogue and difference? Paper presented at Annual Conference of the Philosophy of Education Society of Australasia, http://www2.hawaii.edu/ pesaconf/zpdfs/16white.pdf, accessed 22 July 2013.

Yuval-Davis, N. 2006, 'Intersectionality and feminist politics', European Journal of Women's Studies, vol. 13, no.3, pp. 193-209.

\section{Online resources:}

United Nations Dag Hammarskjöld Library, Archived Documents and Reports from UN Meetings: http://www.un.org/Depts/dhl/udhr/meetings_1948_3rd_3c_ga.shtml , accessed 6 July 2013. 